\title{
Tax gene expression and cell cycling but not cell death are selected during HTLV-1 infection in vivo
}

Linda Zane ${ }^{1}$, David Sibon ${ }^{1,2,7}$, Lionel Jeannin ${ }^{1}$, Marc Zandecki ${ }^{3}$, Marie-Hélène Delfau-Larue ${ }^{4}$, Antoine Gessain ${ }^{5}$, Olivier Gout ${ }^{6}$, Christiane Pinatel ${ }^{1}$, Agnès Lançon ${ }^{1}$, Franck Mortreux ${ }^{1}$, Eric Wattel ${ }^{1,2^{*}}$

\begin{abstract}
Background: Adult T cell leukemia results from the malignant transformation of a CD4 ${ }^{+}$lymphoid clone carrying an integrated HTLV-1 provirus that has undergone several oncogenic events over a 30-60 year period of persistent clonal expansion. Both $\mathrm{CD}^{+}$and $\mathrm{CD} 8^{+}$lymphocytes are infected in vivo; their expansion relies on $\mathrm{CD}^{+}$cell cycling and on the prevention of $\mathrm{CD}^{+}$cell death. Cloned infected $\mathrm{CD} 4^{+}$but not $\mathrm{CD} 8^{+} \mathrm{T}$ cells from patients without malignancy also add up nuclear and mitotic defects typical of genetic instability related to theexpression of the virus-encoded oncogene tax. HTLV-1 expression is cancer-prone in vitro, but in vivo numerous selection forces act to maintain $T$ cell homeostasis and are possibly involved in clonal selection.

Results: Here we demonstrate that the HTLV-1 associated $C D 4^{+}$preleukemic phenotype and the specific patterns of $\mathrm{CD}^{+}$and $\mathrm{CD}^{+}$clonal expansion are in vivo selected processes. By comparing the effects of recent (1 month) experimental infections performed in vitro and those observed in cloned T cells from patients infected for $>6-26$ years, we found that in chronically HTLV-1 infected individuals, HTLV-1 positive clones are selected for tax expression. In vivo, infected $\mathrm{CD}^{+}$cells are positively selected for cell cycling whereas infected $\mathrm{CD}^{+}$cells and uninfected $\mathrm{CD}_{4}^{+}$cells are negatively selected for the same processes. In contrast, the known HTLV-1-dependent prevention of $\mathrm{CD} 8^{+} \mathrm{T}$ cell death pertains to both in vivo and in vitro infected cells.
\end{abstract}

Conclusions: Therefore, virus-cell interactions alone are not sufficient to initiate early leukemogenesis in vivo.

\section{Introduction}

HTLV-1 is the deltaretrovirus that causes adult T-cell leukemia/lymphoma (ATLL) [1] and inflammatory diseases such as tropical spastic paraparesis (TSP)/ HTLV-1-associated myelopathy (HAM) [2]. In vivo, the deltaretrovirus infection is a two-step process that includes an early, transient and intense burst of horizontal replicative dissemination of the virus followed by the persistent clonal expansion of infected cells which encompasses the remaining lifespan of infected organisms [3-6]. Clonal expansion is accompanied by somatic mutations, which are regularly detected in vivo [5,7]. HTLV-1 infects $\mathrm{CD}^{+}$and $\mathrm{CD} 8^{+} \mathrm{T}$ cells that roughly display similar patterns of clonal expansion in carriers

\footnotetext{
* Correspondence: wattel@lyon.fnclcc.fr
'CNRS UMR5239, Université de Lyon, Oncovirologie et Biothérapies, Centre

* Correspondence: wattel@lyon.fnclcc.fr
${ }^{1}$ CNRS UMR5239, Université de Lyon, Oncovirologie et Biothérapies, Centre Léon Bérard, 69008 Lyon, France
}

(c) 2010 Zane et al; licensee BioMed Central Ltd. This is an Open Access article distributed under the terms of the Creative Commons Attribution License (http://creativecommons.org/licenses/by/2.0), which permits unrestricted use, distribution, and reproduction in any medium, provided the original work is properly cited.

without malignancy [8]. Nevertheless, we recently demonstrated that the clonal expansion of HTLV-1 positive $\mathrm{CD}^{+}$and $\mathrm{CD} 4^{+}$lymphocytes relies on two distinct mechanisms: infection prevents cell death in the former whereas it recruits the latter into the cell cycle $[8,9]$. Indeed, cloned infected but not immortalized CD4 ${ }^{+} \mathrm{T}$ cells from patients without malignancy are cycling cells that also add up nuclear and mitotic defects typical of genetic instability, in a Tax dependent manner.

Important and rapid fluctuations in the levels of cell cycling and apoptosis are the hallmark of normal $\mathrm{CD} 4^{+}$ and $\mathrm{CD}^{+}$cells and lie at the heart of the adaptive immune response (reviewed in [10]). For example, naive $\mathrm{CD}^{+}{ }^{+}$and $\mathrm{CD} 8^{+} \mathrm{T}$ cells specific for a particular antigen occur at very low frequencies that may be undetectable in vivo. Upon infection, antigen-specific $\mathrm{CD} 4^{+} \mathrm{T}$ cells can be as many as 1 in 20 in the spleen, and antigenspecific $\mathrm{CD}^{+} \mathrm{T}$ cells may be one in two [10]. After this 
expansion phase, homeostatic control by apoptosis reduces the memory cell population to $\sim 5 \%$ of the peak number of responding $\mathrm{T}$ cells. Modulation of cell cycling and apoptosis are the hallmark of HTLV-1 as several virus-encoded proteins such as Tax, HBZ, p13, p30 and p12 interfere with cell cycling and/or apoptosis [11-13]. For example Tax, which is expressed by both infected $\mathrm{CD}^{+}$and $\mathrm{CD}^{+}$cells, can both stimulate cell cycling and block apoptosis in transfected or transduced cells [14-19].

These wide ranges of cellular and viral capabilities, with regard to cell cycle and apoptosis, contrast with the archetypal behavior of cloned $\mathrm{T}$ cells derived from naturally infected individuals, which links HTLV-1 infection with $\mathrm{CD}^{+}$cell proliferation and $\mathrm{CD} 8^{+}$cell accumulation. Phenotype-specific transcription factor availabilities have been proposed to explain the different consequences of virus expression between $\mathrm{CD}^{+}$and $\mathrm{CD}^{+}$cells $[8,9,20]$. Alternatively, given the positive and negative selection forces that act on HTLV-1 replication throughout the duration of the infection in vivo (reviewed in [21]), the mechanism underlying the clonal expansion of $\mathrm{CD}^{+}$and $\mathrm{CD}^{+}$cells might well have been selected in vivo. Here, we have cloned infected and uninfected $\mathrm{CD}^{+}$and $\mathrm{CD}^{+}$cells derived from TSP/ HAM patients infected for more than 6 to 26 years, and we have compared them for viral expression, morphological alterations, cell cycle and apoptosis with cells derived from a recent in vitro infection and cloned in the same conditions only 1 month after experimental infection. We show that recent and chronic infections protect infected $\mathrm{CD}^{+}$cells from cell death while producing significantly distinct effects on the cell cycle of $\mathrm{CD}^{+}{ }^{+}$and $\mathrm{CD}^{+}$clones, and we provide evidence that the preleukemic phenotype typical of infected $C D 4^{+}$ cells has been selected in vivo.

\section{Materials and methods}

\section{Ethics statement}

This study was conducted according to the principles expressed in the Declaration of Helsinki. The study was approved by the Institutional Review Board of the Léon Bérard anticancer center. All patients provided written informed consent for the collection of samples and subsequent analysis.

\section{Samples studied}

Peripheral blood mononuclear cells (PBMCs) were obtained after informed consent from 4 patients with TSP/HAM and from 5 uninfected blood donors. The HTLV-1-negative acute lymphoblastic leukemia T-cell line Jurkat and the HTLV-1-transformed T-cell lines MT4, MT2 and C91PL were propagated as previously described [22,23].

\section{In vitro infection with HTLV-I}

Fresh PBMCs were separated from HTLV-1-negative donor blood samples by Ficoll (Pancoll, Biotech $\mathrm{GmBH}$ ) density gradient centrifugation. HTLV-1 transmission was performed by co-culturing the PBMCs with lethally irradiated (60 Gy) HTLV-1-positive MT2 cells at a ratio of 5:1, as described elsewhere [24]. The MT2 cell line is known to be chronically infected with HTLV-1 [25]. Co-cultures were maintained for 28 days in six-well plates in $4 \mathrm{ml}$ of RPMI 1640 medium (Gibco, Paisley, United Kingdom) containing $100 \mathrm{U} / \mathrm{ml}$ of recombinant interleukin 2 in the absence of exogenous stimulation such as by phytohemagglutinin (PHA).

\section{T-cell limiting dilution cloning}

PBMCs were cloned by limiting dilution ( 0.1 cell per well) in Terasaki plates after removal of adherent cells. The medium used for T lymphocytes was RPMI 1640 containing penicillin and streptomycin, sodium pyruvate, non-essential amino acid solution, 2-mercaptoethanol, $10 \%$ filtered human $\mathrm{AB}$ serum and $100 \mathrm{U} / \mathrm{mL}$ recombinant IL-2 (Chiron Corporation). For cloning, the medium was supplemented with $1 \mu \mathrm{g} / \mathrm{mL}$ PHA (Abbott Murex HA 16) and $5 \times 10^{5} / \mathrm{mL}$ irradiated (30 Gy) allogeneic PBMCs (feeder cells). The Terasaki plates were stored at $37^{\circ} \mathrm{C}$ for 10 days in aluminium foil, then checked for growing cells under a microscope. Positive cultures were transferred to 96-well U-bottom plates in the medium used for $\mathrm{T}$ lymphocytes, then restimulated. $\mathrm{T}$ lymphocytes were restimulated every 14 days with PHA $(1 \mu \mathrm{g} / \mathrm{mL})$ and fresh feeder cells $\left(10^{6} / \mathrm{mL}\right)$. Lethally irradiated PBMCs from 3 distinct allogeneic, HTLV-I negative donors were used as feeder cells to exclude the possibility of clones becoming infected in vitro. To preserve the original growth characteristics of the cells, clones were maintained this way for no more than 4 months, after which time a fresh aliquot was thawed.

\section{Phenotypic determination}

Antibodies recognizing CD4 and CD8 were purchased from DakoCytomation. For fluorescence-activated cell scanner (FACScan) analysis, PBMCs or cloned T cells were incubated with $5 \%$ filtered human serum, then stained with antibodies. Staining and scanning were performed in phosphate-buffered saline (PBS) with $2 \%$ fetal calf serum (FCS). Isotype-matched controls were used. Data were acquired on a FACScan and analyzed by means of the CellQuest ${ }^{\mathrm{Tm}}$ software (Becton Dickinson).

\section{Apoptosis assay}

Apoptosis was assessed using the APOPTEST ${ }^{\mathrm{Tm}}$ kit (DakoCytomation) containing fluorescein-conjugated annexin $\mathrm{V}$, propidium iodide (PI) and binding buffer. Cells suspended in the binding buffer were mixed with 
fluorescein-conjugated annexin V and PI. After 10-minute incubation, cells were analyzed by FACScan. By combining annexin V/FITC and PI, three distinct phenotypes could be discriminated: unlabeled non-apoptotic live cells, apoptotic cells labeled by annexin V/FITC, and necrotic cells (necrosis or late apoptosis) labeled by both annexin V/FITC and PI. Overall, for each sample analyzed, this experiment permitted the categorization of the cells as viable $\left(\mathrm{AnnV}^{-} / \mathrm{PI}^{-}\right)$, early apoptotic $\left(\mathrm{AnnV}^{+} / \mathrm{PI}^{-}\right)$, late apoptotic $\left(\mathrm{AnnV}^{+} / \mathrm{PI}^{+}\right)$or dead $\left(\mathrm{AnnV}^{-} / \mathrm{PI}^{+}\right)$.

\section{Cell cycle analysis}

Cell cycle distribution was assessed by measuring the DNA content of a suspension of fresh nuclei by flow cytometric analysis after PI staining. Cloned T cells $(5 \times$ $10^{5}$ ) were washed with PBS. The supernatant was discarded, and cells were permeabilized with $250 \mu \mathrm{L}$ of $70 \%$ ethanol for 30 minutes at $4{ }^{\circ} \mathrm{C}$ with rotation. After ethanol elimination, cells were resuspended in $125 \mu \mathrm{L}$ PBS. After storage at $4^{\circ} \mathrm{C}$ for a few hours, cells $(>10,000)$ were labeled by PI in the presence of RNase A (Sigma), scanned by flow cytometry and then analyzed with the ModFit LT $^{\mathrm{TM}}$ software.

\section{Polymerase chain reaction}

T-cell clones were screened for HTLV-I proviral DNA by polymerase chain reaction (PCR) amplification with LTR-specific primers, as previously described [26]. Inverse PCR (IPCR) amplification of HTLV-1 3' LTRs and flanking sequences was carried out on the DNA extracted from cloned $\mathrm{T}$ cells, as previously described [8]. Expression of tax was quantified by real-time quantitative RT-PCR, as described [27]. Analysis of TCRgamma chain gene rearrangements was performed on the DNA extracted from generated clones, as previously described [28]. This permitted confirmation of the monoclonality of the corresponding cultured cells. Products from multiplex PCR were run on a denaturating gradient gel, which enabled the detection of a band and gave a specific imprint of a given $\mathrm{T}$-cell clone, if the clone accounted for at least $1 \%$ of the total lymphocytes present in the sample.

\section{Molecular cloning and sequencing}

Purified products from IPCR experiments were phosphorylated using T4 polynucleotide kinase (Pharmacia, Uppsala, Sweden), then ligated with SmaI-digested (Pharmacia) and dephosphorylated M13mp18 replicative form DNA (New England Biolabs), as previously described ${ }^{12,32}$. After transformation of Escherichia coli XL1 by electroporation, recombinant M13 plaques were screened by hybridization with the HTLV-1 LTR-specific ${ }^{32} \mathrm{P}$-labeled oligonucleotide BIO5. Single-stranded templates were sequenced using fluorescent dideoxynucleotides (Perkin
Elmer). The products were resolved on an Applied Biosystems 377A DNA sequencer (Perkin Elmer) with 377A software (Perkin Elmer). Sequence alignments were performed with the Sequence Navigator Software (Perkin Elmer).

\section{Results}

Figure 1 summarizes the strategy used for comparing the effects of in vitro infection and persistent in vivo infection on the behavior of $\mathrm{CD}^{+}$and $\mathrm{CD}^{+}$cells. $\mathrm{T}$-cell limiting dilution cloning of PBMCs from the 4 TSP/HAM patients allowed us to clone uninfected and naturally infected $\mathrm{CD}_{4}^{+}$and $\mathrm{CD}^{+}$cells from the same infected individuals [8]. This permitted us to enrich our previously published library of in vivo derived clones [8]. PBMCs from Patient 1 have been previously assayed for clonal expansion and 3' flanking sequence analyses on several occasions [4,29-31]. IPCR products from 4 clones generated by limiting dilution cloning of patient 1 PBMCs were sequenced and, for $1 \mathrm{CD}^{+}$clone, the 3' provirus integration site sequence matched that identified in PBMCs collected 7 years earlier (Figure 2). This indicates that the present cloning strategy allows for the analysis of in vivo infected and persistently expanded clones. In vitro HTLV-1 cellular infection was performed herein by co-culturing PBMCs isolated from healthy adult donors, seronegative for HTLV-1/2, HIV, $\mathrm{HBV}$, and HCV, with lethally irradiated MT2 [24]. Cells were next cloned and cultured as PBMCs from HAM/ TSP, and all generated clones were assayed for HTLV-1 infection, tax expression, $\mathrm{CD}^{+}$and $\mathrm{CD}^{+}$expression, cell cycling and apoptosis, as shown in Figure 1 and as detailed in the Methods section. Clonal efficiency was identical for in vivo- and in vitro- derived cells. Table 1 represents the distribution of analyzed $\mathrm{T}$ cell clones according to the route of infection. All 152 clones harbored distinct and unique TCR, as evidenced by multiplex PCR-gamma-DGGE [8]. Infected and uninfected clones were not immortalized and required IL-2 and stimulation with PHA and feeder cells at 14-day intervals for continued growth. MT2 cells harbor 18 integrated proviruses per cell [24], and its level of tax expression was measured as 25274.3 arbitrary units (AU). At day 7 of co-culture of fresh PBMCs with irradiated MT2 cells, inverse PCR failed to detect any MT2 specific HTLV-1 integration site; at this time point, the proviral copies detected corresponded to newly infected cells. Therefore, subsequently cloned $\mathrm{CD}^{+}$and $\mathrm{CD}^{+}$cells corresponded to bona fide newly infected cells in vitro.

Given that tax expression correlates with infected $\mathrm{T}$ cell behavior [14-19], we compared the amounts of tax transcripts between in vitro and in vivo infected cells. Figure 3 represents the distribution of tax expression in the 79 infected $\mathrm{CD}^{+}$and $\mathrm{CD}^{+}$clones. In 7 of the 24 


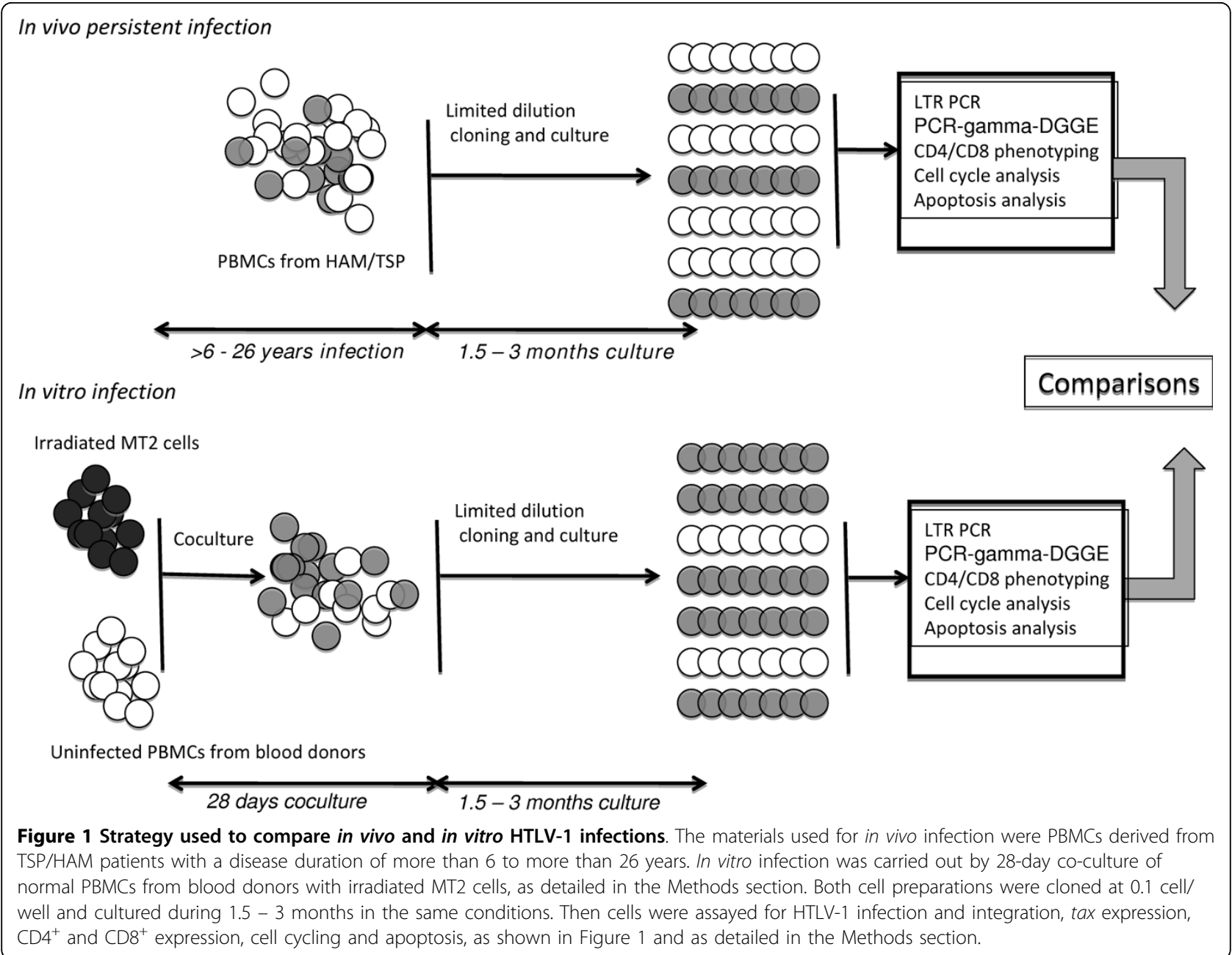

in vitro HTLV-1 infected clones screened (29\%), the amount of tax expression was above the detection threshold: 4/12 $\mathrm{CD}^{+}$(33\%) and 3/12 $\mathrm{CD}^{+}$(25\%) clones. In tax positive clones derived from in vitro infection, the HTLV-1 tax mRNA load ranged from 16.7 to 474.5 AU (mean \pm se of mean $114.1 \pm 61.0$ ) without significant difference between $\mathrm{CD}^{+}{ }^{+}$(mean \pm se of mean $43.0 \pm 11.1$ ) and $\mathrm{CD}^{+}$cells (mean \pm se of mean $208.7 \pm$ 134.1). In 50 of the 55 in vivo HTLV-1 infected clones screened ( 91\%), the amount of tax expression was above the detection threshold: $33 / 36 \mathrm{CD}^{+}(91.7 \%)$ and $17 / 19$ (89.5\%) $\mathrm{CD}^{+}$clones. In these tax positive clones derived from TSP/HAM, the HTLV-1 tax mRNA load ranged from 41.5 to $603475.5 \mathrm{AU}$ (mean \pm se of mean $139816.0 \pm 30965)$ without significant difference between $\mathrm{CD}^{+}{ }^{+}$and $\mathrm{CD}^{+}{ }^{+}$clones. For both $\mathrm{CD} 4^{+}$and $\mathrm{CD}^{+}$cells, the frequency of tax positive clones was significantly higher in cells derived from in vivo infection $\left(\mathrm{p}=0.001\right.$ for $\mathrm{CD} 4^{+}$and $\mathrm{CD} 8^{+}$clones, Fisher exact test) and the level of tax expression in tax positive clones was significantly higher in $\mathrm{CD}^{+}$or $\mathrm{CD}^{+}$clones derived from TSP/HAM than in those generated after experimental infection $\left(\mathrm{p}<10-4\right.$ for tax $+-\mathrm{CD} 4^{+}$clones, $\mathrm{p}=$ 0.048 for tax $+-\mathrm{CD} 8^{+}$clones, Mann Whitney test) (Figure $3)$. These results indicate that in vitro infection generates infected $\mathrm{CD}^{+}$and $\mathrm{CD}^{+}$clones exhibiting significantly lower amounts of tax mRNA than cloned $\mathrm{T}$ cells from TSP/HAM. This allowed us to conclude that, in vivo, persistent infection selects tax-expressing clones.

In vivo infection has been found to trigger cellular morphological changes that depend on the $\mathrm{T}$ cell phenotype and tax expression [8,9]. Cell morphology was therefore analyzed in all infected and uninfected clones and compared between cells derived from in vivo and in vitro infections. Clones derived from in vitro infection did not display significantly different patterns of morphological changes after infection. For $\mathrm{CD} 4^{+}$clones, the proportions of multinucleated cells in uninfected versus infected clones were $0.023 \%$ and $0.016 \%$, respectively [not significant (NS)]. These values were $0.04 \%$ and $0.44 \%$ for $\mathrm{CD}^{+}$clones (NS), without significant correlation between tax expression and cell morphology. In 


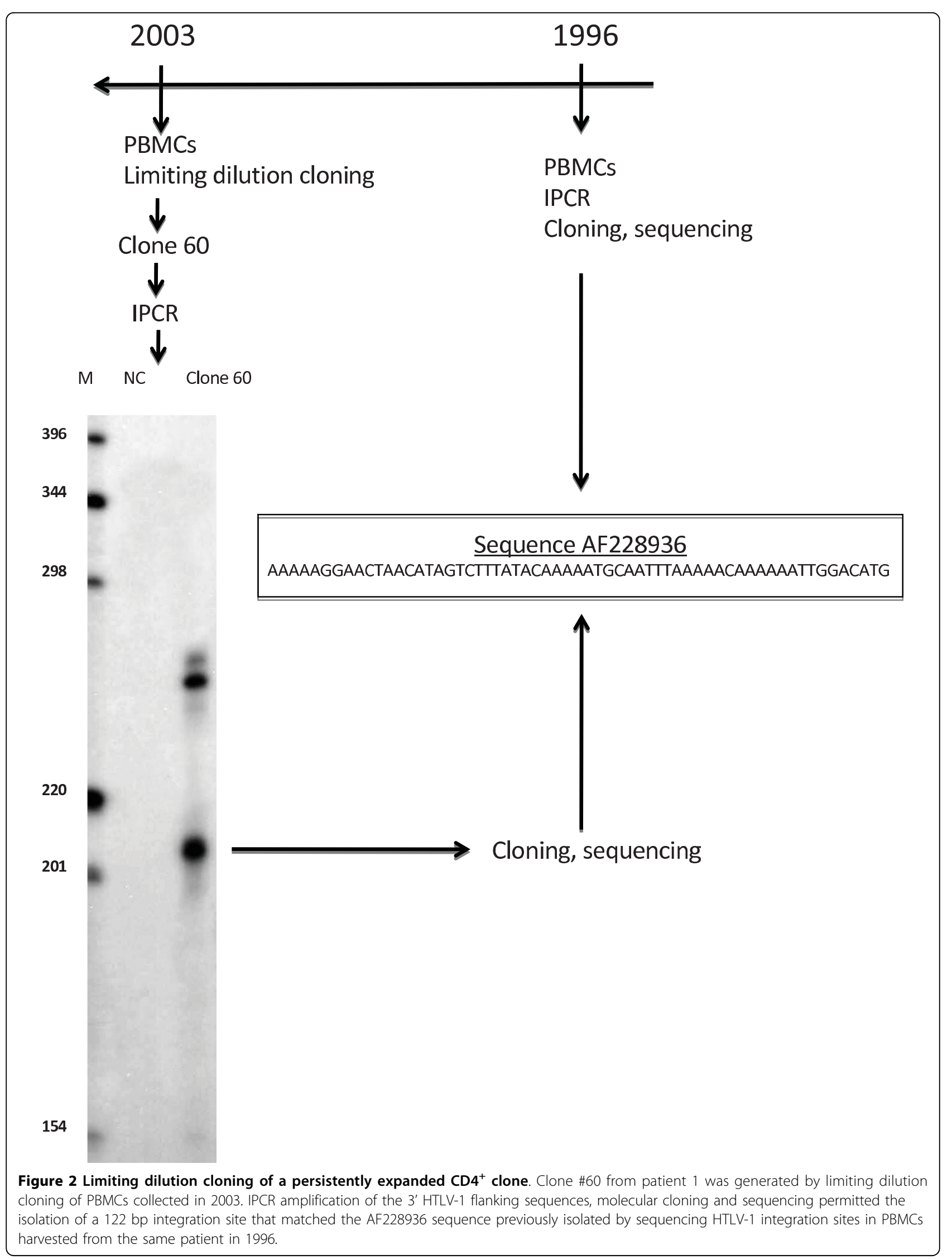


Table 1 Distribution of cloned lymphoid cells according to HTLV-1 infection

\begin{tabular}{lcccc}
\hline & \multicolumn{2}{c}{ In vitro infection } & \multicolumn{2}{c}{ In vivo infection } \\
\hline & CD4+ & CD8+ & CD4+ & CD8+ \\
\hline Uninfected & 20 & 20 & 18 & 15 \\
Infected & 12 & 12 & 36 & 19 \\
\hline
\end{tabular}

contrast and as already described [8], infected clones derived from patients with HAM/TSP displayed multinuclearity and impaired cytokinesis, with the presence of chromatin bridges almost exclusively restricted to CD4 ${ }^{+}$HTLV-1 positive clones and correlated with the level of tax expression. For example, the proportions of multinucleated cells in infected versus uninfected cloned $\mathrm{CD} 4{ }^{+}$cells derived from TSP/HAM were $2.06 \%$, and $0.05 \%$, respectively $(\mathrm{p}=0.01$, Mann-Whitney test $)$. These values were $0.08 \%$ and $0.51 \%$ for $\mathrm{CD}^{+}$cells (NS). Multinuclearity correlated with $\operatorname{tax}$ expression $(\mathrm{R}=$ $0.829, \mathrm{p}=0.002$, Spearman rank correlation). These results indicate that newly in vitro infected $\mathrm{CD} 4^{+}$lymphocytes do not display the typical cellular features of genetic instability that characterize in vivo infected $\mathrm{CD} 4^{+}$clones.

After having characterized in vitro and in vivo infected clones for tax expression and cell morphology, we next compared the effects of in vitro and in vivo infections on the cell cycle. The percentages of MT2 cells in the G0G1, G2M and S phases of the cycle were respectively $89 \%, 3 \%$, and $8 \%$. For all clones, the cell cycle was assessed by flow cytometry at day 6 following PHA stimulation after 1.5 to 2.5 months of culture (Figure 1), as detailed in the Methods section. Figure $4 \mathrm{~A}$ represents fluctuations of cell cycle distribution for infected or uninfected $\mathrm{CD} 4^{+}$and $\mathrm{CD} 8^{+}$ clones derived from in vitro versus in vivo infection, respectively. For the $32 \mathrm{CD}^{+}$clones derived from in vitro infection, there was no significant difference in cell distribution across the phases of the cell cycle between HTLV-1 positive and negative lymphocytes (Figure 4A). Conversely, cell distribution across the phases of the cell cycle was significantly different between infected and uninfected $\mathrm{CD}^{+}$lymphocytes (Figure $2 \mathrm{~A}$ ) cloned after in vitro infection. Overall, the percentages of $\mathrm{CD} 8^{+}$lymphocytes left uninfected after in vitro infection in the G0G1, G2M and S phases of the cycle were respectively $86 \%, 3 \%$, and $11 \%$, versus $81 \%, 3 \%$, and $16 \%$ for in vitro infected lymphocytes ( $\mathrm{p}=0.035$ for cells in the S phase, MannWhitney test). There was no correlation between tax expression and cell distribution across the phases of the cell cycle for either $\mathrm{CD} 4^{+}$and $\mathrm{CD} 8^{+}$clones derived from in vitro infection. For the 55 infected clones derived from in vivo persistent infection, i.e. from PBMCs of patients with HAM/TSP, results of cell cycle analysis paralleled and even surpassed those previously published [8], with a significant redistribution of $\mathrm{CD} 44^{+}$lymphocytes from the G0/G1 phase towards the S and G2M phases of the cell cycle (Figure 4A). In contrast, upon in vivo infection, there was no significant cell cycle alteration for $\mathrm{CD}^{+}$clones. For infected clones derived from TSP/HAM, the tax mRNA load correlated negatively with the percentage of cells in the G0G1 phase of the cycle ( $<10-4, \mathrm{R}-0.629$, Spearman rank correlation) and positively with the percentage of cells in the G2M and $S$ phases $(p=0.001$, $\mathrm{R} 0.621$, Spearman rank correlation). These results indicate that newly in vitro infected $\mathrm{CD} 4^{+}$or $\mathrm{CD} 8^{+}$cells display cell cycle alterations significantly distinct from those of chronically infected $\mathrm{CD} 4^{+}$or $\mathrm{CD} 8^{+}$cells derived from TSP/HAM. Figure 4A shows that these differences were based on significantly distinct cell cycle distributions between in vitro and in vivo infected clones and, surprisingly, also between uninfected clones derived from in vitro versus in vivo infection. For infected $\mathrm{CD}_{4}^{+}$clones, the

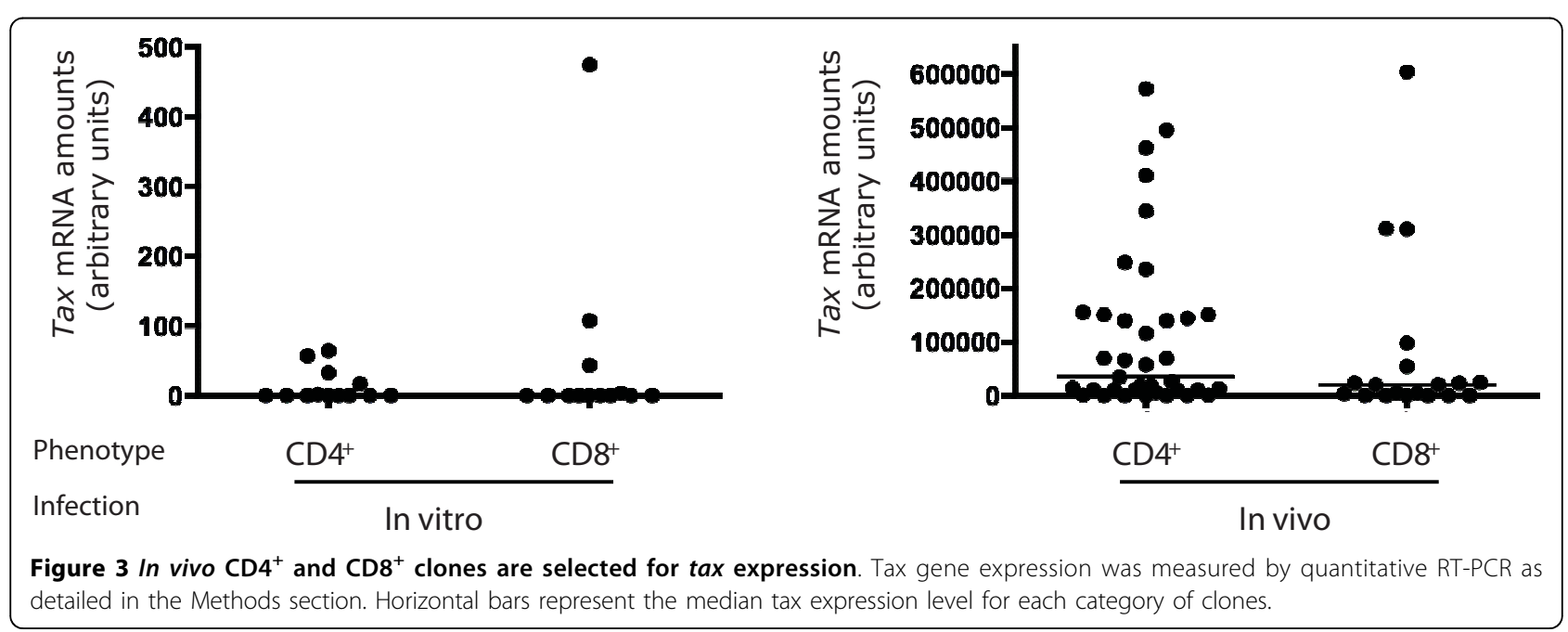




\section{A}

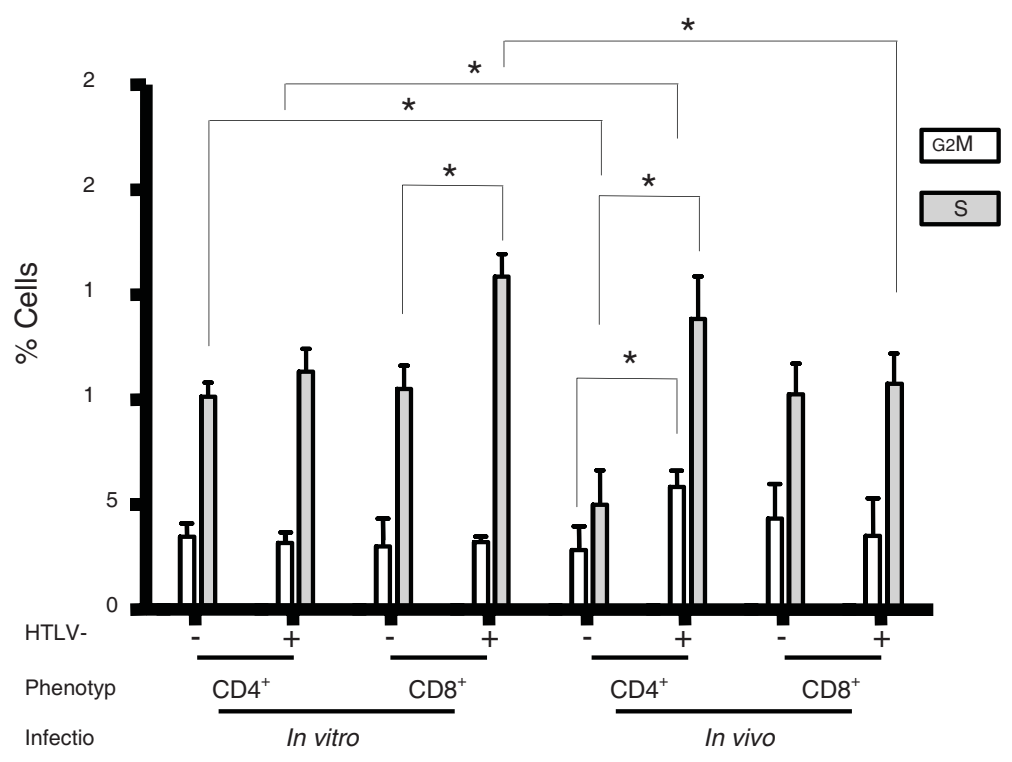

B

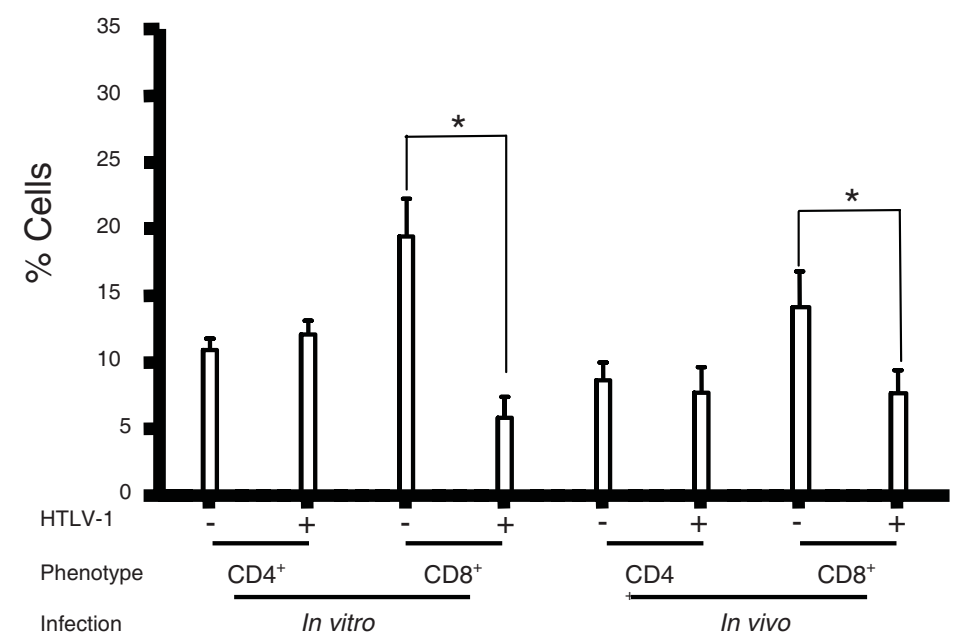

Figure 4 Cell cycling but not cell death is selected during HTLV-1infection in vivo. CD4 ${ }^{+}$and $C D 8^{+}$clones (152 clones) were analyzed at day 6 from PHA stimulation for cell cycle (A) and apoptosis (B). ${ }^{*} p<0.05$.

proportion of in vitro infected cells within the G2M phase of the cell cycle was significantly lower than that of infected $\mathrm{CD}^{+}{ }^{+}$cells derived from TSP/HAM (3.3 versus $5.9, \mathrm{p}<10^{-4}$, Mann Whitney test) (Figure 4A). On the contrary, the proportion of cells left uninfected after in vitro infection and within the $\mathrm{S}$ phase of the cell cycle was significantly higher than that of uninfected $\mathrm{CD} 4^{+}$cells derived from TSP/HAM (10.3 versus 5.1, $\mathrm{p}=0.004$, Mann
Whitney test). For $\mathrm{CD}^{+}$infected clones, the proportion of cells within the $\mathrm{S}$ phase of the cell cycle was significantly higher in vitro than in vivo (16 versus $11.7, \mathrm{p}=0.04$, Mann Whitney test). There was no significant difference in cell distribution across the phases of the cell cycle between in vitro and in vivo infection for uninfected $\mathrm{CD}^{+}$ clones. These results indicate that both infected and uninfected lymphocytes from chronically infected organisms 
have acquired specific cell cycle distribution patterns distinguishing them from newly virus-exposed cells. We conclude that persistent in vivo infection selects specific lymphoid phenotypes with respect to the cell cycle.

For all clones, cell death was assessed by flow cytometry at day 6 following PHA stimulation after 1.5 to 2.5 months of culture (Figure 1), as detailed in the Methods section. For the MT2 cell line, the percentage of apoptotic cells was $5.3 \%$. Figure $4 \mathrm{~B}$ represents fluctuations of apoptotic cell distribution for infected and uninfected $\mathrm{CD}^{+}{ }^{+}$and $\mathrm{CD} 8^{+}$clones derived from in vivo versus in vitro infection, respectively. In contrast to cell cycle analysis, cell death analysis yielded roughly identical results for in vitro and in vivo infections (Figure 4B). For CD4 ${ }^{+}$ clones derived from in vitro or in vivo infection, there was no significant difference in cell viability, apoptosis and necrosis (necrosis and late apoptosis), between HTLV-1 positive and negative lymphocytes. In contrast, the percentage of apoptotic cells was significantly decreased in infected $\mathrm{CD} 8^{+}$cells, both in vitro $(6 \%$ versus $19 \%, \mathrm{p}=0.017$, Mann-Whitney test) and in vivo ( $10 \%$ versus $14.8 \%, \mathrm{p}=0.048$, Mann-Whitney test). The level of tax expression did not influence apoptosis, necrosis and cell viability in in vitro or in vivo $\mathrm{CD} 4^{+}$or $\mathrm{CD}^{+}$infected clones. For $\mathrm{CD} 4^{+}$and $\mathrm{CD}^{+}$clones, there was no significant difference in the proportion of apoptotic cells between in vitro and in vivo infected or uninfected cells. These results indicate that both in vitro and in vivo infections have the same effect on cell death in $\mathrm{CD}^{+}$and $\mathrm{CD}^{+}$clones.

\section{Discussion}

Our data show that persistent in vivo HTLV-1 infection selects tax-expressing clones and specific cell behaviors, with respect to apoptosis and cell cycle. In vitro and in vivo HTLV-1 infections have significantly distinct effects on the proliferation, but not on the accumulation of infected $\mathrm{CD} 4^{+}$and $\mathrm{CD} 8^{+}$cells. Regarding the cell cycle, the known HTLV-1-dependent recruitment of infected $\mathrm{CD}^{+}$cells into the cell cycle [8] appears restricted to the persistent infection while in vitro infection has been found to trigger $\mathrm{CD}^{+}$cell cycling. In contrast, regarding apoptosis, the known HTLV-1dependent prevention of $\mathrm{CD} 8^{+} \mathrm{T}$ cell death appears to pertain to both in vivo and in vitro infected clones. These differences indicate that, in chronically HTLV-1 infected patients, infected $\mathrm{CD} 4^{+}$cells are positively selected for tax expression and cell cycling whereas infected $\mathrm{CD}^{+}$cells and uninfected $\mathrm{CD} 4^{+}$cells are negatively selected for the same processes. Importantly, the preleukemic phenotype of infected $\mathrm{CD} 4^{+}$cells has been found restricted to clones derived from persistently in vivo infected cells.
Tax combines a positive effect on cell cycle with a negative effect on apoptosis [14-19]. Furthermore Tax is the immunodominant target antigen recognized by virus-specific cytotoxic $\mathrm{T}$ lymphocytes (CTLs) (reviewed in [21]) that kill $\mathrm{CD}^{+}$cells naturally infected with HTLV-I and expressing Tax in vitro via a perforindependent mechanism [32]. Tax expression has been found to be influenced by mutations [33], 5'LTR deletion [34] or methylation [35], and integration site position [36,37]. Given the cell-associated replication of HTLV-1, Tax expression appears ambivalent for infected cells. On the one hand it promotes cell cycling and cell accumulation and thereby the clonal expansion of infected cells, whereas on the other hand it exposes infected cells to CTL-mediated lysis. After limiting dilution cloning, more than $90 \%$ of in vivo derived HTLV-1 positive clones retain the capacity to express tax versus less than $30 \%$ of in vitro generated clones. This selection of $\operatorname{tax}$ positive clones in vivo indicates that the ability to express tax is crucial for persistent clonal expansion of infected $\mathrm{CD} 4^{+}$or $\mathrm{CD} 8^{+}$cells in vivo.

Prevention of cell death governs the clonal expansion of infected $\mathrm{CD} 8^{+}$cells in vivo $[8,9]$. Here we have found that HTLV-1 prevents $\mathrm{CD} 8^{+}$cell death both in vitro and in vivo (Figure 4), suggesting that this mechanism of infected $\mathrm{CD}^{+}$clonal expansion does not undergo any specific selection during chronic infection. In addition, in vitro infection redistributed $\mathrm{CD}^{+}$lymphocytes from the G0/G1 phase towards the $S$ phase of the cell cycle whereas no significant phase distribution difference was seen between uninfected and infected $\mathrm{CD}^{+}$clones derived from TSP/HAM. Thus, as $\mathrm{CD} 4^{+}$cells, CD ${ }^{+}$ cells can be redistributed across the cell cycle upon infection. This finding rules out the previous assumption that phenotype-dependent transcription factor availability governs the phenotype-specific consequences of infection on cell cycling $[8,9]$. However, the cycling of infected $\mathrm{CD} 8^{+}$cells is dramatically slowed down in vivo, towards a cell distribution identical to that of uninfected cells (Figure 4A). Thus in the present model, HTLV-1 can both stimulate the cell cycle and prevent the cell death of non-transformed $\mathrm{CD} 8^{+}$lymphocytes whereas the clonal expansion of these infected cells remains restricted to apoptosis inhibition in vivo. This indicates that in vivo, infected $\mathrm{CD} 8^{+}$cells are negatively selected for cell cycling.

For $\mathrm{CD} 4^{+}$cells, experimental in vitro infection had only modest effects on cell cycling and apoptosis while our experiments confirmed and extended the known positive effect of infection on $\mathrm{CD}_{4}^{+}$cell cycling in vivo $[8,9]$. In fact for infected $\mathrm{CD} 4^{+}$clones, the proportion of cycling cells was significantly higher in vivo than in vitro whereas, surprisingly, for uninfected $\mathrm{CD} 4^{+}$clones, this 
proportion was significantly lower in vivo than in vitro. From these differences we concluded that in chronically infected patients, infected $\mathrm{CD} 4^{+}$cells are positively selected for cell cycling whereas uninfected $\mathrm{CD} 4^{+}$cells are negatively selected for the same process. Like cell cycling, cellular morphological changes typical of genetic instability were found restricted to in vivo infected $\mathrm{CD} 4^{+}$ cells, with a statistically significant correlation between tax expression, cells distribution across the phases of the cell cycle, and morphological abnormalities. In contrast, recently in vitro infected $\mathrm{CD} 4^{+}$cells did not display significant morphological changes. Thus the preleukemic phenotype that characterizes HTLV-1 positive $\mathrm{CD} 4^{+}$cells is restricted to in vivo infected cells, meaning that it has been selected during persistent infection.

Hitherto, two factors have been considered to rule HTLV-1 replication and pathogenicity: the effects of HTLV-1 encoded proteins on both the virus and its host cells; and the consequences of the robust antiHTLV-1 CTL response, which mainly target Taxexpressing cells. By showing that uninfected $\mathrm{CD} 4^{+}$cells from TSP/HAM are negatively selected for cell cycling, the present results suggest that additional forces disturb $\mathrm{T}$-cell homeostasis in infected individuals. Uninfected $\mathrm{CD}^{+}$cells account for the majority of the T-cell repertoire in infected individuals, and their impairment for cell cycling might be expected to foster immunosuppression and therefore contribute to leukemogenesis, inflammation, and susceptibility of infected individuals to certain opportunistic diseases.

In conclusion this work demonstrates that persistent HTLV-1 infection selects specific lymphoid phenotypes including the preleukemic features of $\operatorname{tax}$ positive $\mathrm{CD} 4^{+}$ clones,- with respect to cell cycling and that these involve both infected and uninfected cells. This selection results in fixed phenotypes, as evidenced after 1.5 to 3 months of cell culture in vitro. Tax is the main target for the antiHTLV-1 cellular immune response (CTL), and tax expression correlates with cell cycling and cellular morphological changes. Given that infection selects tax-expressing clones in vivo, it could be speculated that the CTL response participates in the imprinted selection of infected cell cycling especially for $\mathrm{CD}^{+}{ }^{+}$cells, and thereby in deciding the mechanism of clonal expansion in vivo. However additional factors necessarily account for the selection of the specific phenotype of uninfected clones derived from TSP/ HAM. Whether these patterns of clonal expansion contribute to maintain a normal and constant lymphocyte pool throughout the infection remains to be elucidated. Furthermore it will be interesting to test whether the infection also selects for the expression of additional HTLV-1 encoded proteins. Finally, as the preleukemic phenotype characterizing infected $\mathrm{CD} 4^{+}$cells is restricted to in vivo derived clones, the present findings suggest that virus-cell interactions alone are not sufficient for initiating early leukemogenesis in vivo. This supports the current limiting dilution cloning strategy as an appropriate tool for investigating HTLV-1-associated oncogenesis in naturally infected cells.

\section{Acknowledgements}

This work was supported by the Ligue Nationale Contre le Cancer (Comités de l'Ain, de la Drome et du Rhône), the Association pour la Recherche sur le Cancer, the Fondation de France, the Association Laurette Fugain, the Centre Léon Bérard, the Centre National pour la Recherche Scientifique and the Institut National de la Santé et de la Recherche Médicale. LZ was supported by a bursary from the Association pour la Recherche sur le Cancer and from the Ligue Nationale Contre le Cancer (comité de la Loire). FM is supported by Inserm. EW is supported by the Hospices Civils de Lyon and Lyon I University. The authors thank Marie-Dominique Reynaud for the preparation of the manuscript.

\section{Author details}

'CNRS UMR5239, Université de Lyon, Oncovirologie et Biothérapies, Centre Léon Bérard, 69008 Lyon, France. ${ }^{2}$ Hôpital Edouard Herriot, Service d'Hématologie, Pavillon E, Lyon, France. ${ }^{3} \mathrm{CHU}$ d'Angers, Laboratoire d'Hématologie, Angers, France. ${ }^{4} \mathrm{CHU}$ Henri Mondor, Laboratoire d'Immunologie, Créteil, France. ${ }^{5}$ Institut Pasteur, Unité d'Epidémiologie et Physiopathologie desVirus Oncogènes, Institut Pasteur, Paris, France.

${ }^{6}$ Fondation Rothschild, Service de Neurologie, Paris, France. ${ }^{7}$ Current address: Hémato-oncologie, Hôpital Saint-Louis, APHP, Université Paris VII, 1 avenue Claude Vellefaux, 75010 Paris, France.

\section{Authors' contributions}

$L Z$, DS designed the research, performed the research and analyzed the data. $L J, M Z, C P, M H D L$ and $A L$ performed the research FM, and EW designed the research and analyzed the data. $A G$ and $O G$ contributed vital new reagents. EW wrote the paper.

\section{Competing interests}

The authors declare that they have no competing interests.

Received: 11 November 2009 Accepted: 11 March 2010 Published: 11 March 2010

\section{References}

1. Uchiyama T, Yodoi J, Sagawa K, Takatsuki K, Uchino H: Adult T-cell leukemia: clinical and hematologic features of 16 cases. Blood 1977, 50:481-492.

2. Gessain A, Barin F, Vernant JC, Gout O, Maurs L, Calender A, de The G: Antibodies to human T-lymphotropic virus type-I in patients with tropical spastic paraparesis. Lancet 1985, 2:407-410.

3. Mortreux F, Gabet AS, Wattel E: Molecular and cellular aspects of HTLV-1 associated leukemogenesis in vivo. Leukemia 2003, 17:26-38.

4. Mortreux F, Kazanji M, Gabet AS, de Thoisy B, Wattel E: Two-step nature of human T-cell leukemia virus type 1 replication in experimentally infected squirrel monkeys (Saimiri sciureus). J Virol 2001, 75:1083-1089.

5. Mortreux F, Leclercq I, Gabet AS, Leroy A, Westhof E, Gessain A, WainHobson S, Wattel E: Somatic mutation in human T-cell leukemia virus type 1 provirus and flanking cellular sequences during clonal expansion in vivo. J Nat/ Cancer Inst 2001, 93:367-377.

6. Pomier C, Alcaraz MT, Debacq C, Lancon A, Kerkhofs P, Willems L, Wattel E, Mortreux F: Early and transient reverse transcription during primary deltaretroviral infection of sheep. Retrovirology 2008, 5:16.

7. Moules V, Pomier C, Sibon D, Gabet AS, Reichert M, Kerkhofs P, Willems L, Mortreux $F$, Wattel E: Fate of premalignant clones during the asymptomatic phase preceding lymphoid malignancy. Cancer Res 2005, 65:1234-1243.

8. Sibon D, Gabet AS, Zandecki M, Pinatel C, Thete J, Delfau-Larue MH, Rabaaoui S, Gessain A, Gout O, Jacobson S, Mortreux F, Wattel E: HTLV-1 propels untransformed CD4 lymphocytes into the cell cycle while protecting CD8 cells from death. J Clin Invest 2006, 116:974-983. 
9. Zane L, Sibon D, Mortreux F, Wattel E: Clonal expansion of HTLV-1 infected cells depends on the CD4 versus CD8 phenotype. Front Biosci 2009, 14:3935-3941.

10. Callard R, Hodgkin P: Modeling T- and B-cell growth and differentiation. Immunol Rev 2007, 216:119-129.

11. Matsuoka M, Jeang KT: Human T-cell leukaemia virus type 1 (HTLV-1) infectivity and cellular transformation. Nat Rev Cancer 2007, 7:270-280.

12. Saggioro D, Silic-Benussi M, Biasiotto R, D'Agostino DM, Ciminale V: Control of cell death pathways by HTLV-1 proteins. Front Biosci 2009, 14:3338-3351.

13. Boxus M, Twizere JC, Legros S, Dewulf JF, Kettmann R, Willems L: The HTLV-1 Tax interactome. Retrovirology 2008, 5:76.

14. Sieburg M, Tripp A, Ma JW, Feuer G: Human T-cell leukemia virus type 1 (HTLV-1) and HTLV-2 tax oncoproteins modulate cell cycle progression and apoptosis. J Virol 2004, 78:10399-10409.

15. Haoudi A, Daniels RC, Wong E, Kupfer G, Semmes OJ: Human T-cell leukemia virus-I tax oncoprotein functionally targets a subnuclear complex involved in cellular DNA damage-response. J Biol Chem 2003, 278:37736-37744.

16. Jeang KT, Widen SG, Semmes OJt, Wilson SH: HTLV-I trans-activator protein, tax, is a trans-repressor of the human beta-polymerase gene. Science 1990, 247:1082-1084.

17. Neuveut $C$, Jeang KT: Cell cycle dysregulation by HTLV-I: role of the tax oncoprotein. Front Biosci 2002, 7:D157-163.

18. Neuveut C, Low KG, Maldarelli F, Schmitt I, Majone F, Grassmann R, Jeang KT: Human T-cell leukemia virus type 1 Tax and cell cycle progression: role of cyclin D-cdk and p110Rb. Mol Cell Biol 1998, 18:3620-3632.

19. Liang MH, Geisbert T, Yao Y, Hinrichs SH, Giam CZ: Human T-lymphotropic virus type 1 oncoprotein tax promotes S-phase entry but blocks mitosis. J Virol 2002, 76:4022-4033.

20. Newbound GC, Andrews JM, O'Rourke JP, Brady JN, Lairmore MD: Human T-cell lymphotropic virus type 1 Tax mediates enhanced transcription in CD4 ${ }^{+}$T lymphocytes. J Virol 1996, 70:2101-2106.

21. Bangham CR, Meekings K, Toulza F, Nejmeddine M, Majorovits E, Asquith B, Taylor GP: The immune control of HTLV-1 infection: selection forces and dynamics. Front Biosci 2009, 14:2889-2903.

22. Cavrois M, Wain-Hobson S, Wattel E: Stochastic events in the amplification of HTLV-I integration sites by linker-mediated PCR. Res Virol 1995, 146:179-184.

23. Gabet AS, Mortreux F, Charneau P, Riou P, Duc-Dodon M, Wu Y, Jeang KT, Wattel E: Inactivation of hTERT transcription by Tax. Oncogene 2003, 22:3734-3741.

24. Rabaaoui S, Zouhiri F, Lancon A, Leh H, d'Angelo J, Wattel E: Inhibitors of strand transfer that prevent integration and inhibit human T-cell leukemia virus type 1 early replication. Antimicrob Agents Chemother 2008, 52:3532-3541.

25. Mohapatra S, Chu B, Wei S, Djeu J, Epling-Burnette PK, Loughran T, Jove R, Pledger WJ: Roscovitine inhibits STAT5 activity and induces apoptosis in the human leukemia virus type 1-transformed cell line MT-2. Cancer Res 2003, 63:8523-8530.

26. Saito M, Furukawa $Y$, Kubota R, Usuku K, Izumo S, Osame M, Yoshida M: Mutation rates in LTR of HTLV-1 in HAM/TSP patients and the carriers are similarly high to Tax/Rex-coding sequence [see comments]. $J$ Neurovirol 1996, 2:330-335.

27. Yamano $Y$, Nagai M, Brennan M, Mora CA, Soldan SS, Tomaru U, Takenouchi N, Izumo S, Osame M, Jacobson S: Correlation of human T-cell lymphotropic virus type 1 (HTLV-1) mRNA with proviral DNA load, virusspecific CD8(+) T cells, and disease severity in HTLV-1-associated myelopathy (HAM/TSP). Blood 2002, 99:88-94

28. Theodorou I, Bigorgne C, Delfau MH, Lahet C, Cochet G, Vidaud M, Raphael M, Gaulard P, Farcet JP: VJ rearrangements of the TCR gamma locus in peripheral T-cell lymphomas: analysis by polymerase chain reaction and denaturing gradient gel electrophoresis. J Pathol 1996, 178:303-310.

29. Cavrois M, Gessain A, Gout O, Wain-Hobson S, Wattel E: Common human T cell leukemia virus type 1 (HTLV-1) integration sites in cerebrospinal fluid and blood lymphocytes of patients with HTLV-1-associated myelopathy/tropical spastic paraparesis indicate that HTLV-1 crosses the blood-brain barrier via clonal HTLV-1-infected cells. J Infect Dis 2000 182:1044-1050.
30. Cavrois M, Gessain A, Wain-Hobson S, Wattel E: Proliferation of HTLV-1 infected circulating cells in vivo in all asymptomatic carriers and patients with TSP/HAM. Oncogene 1996, 12:2419-2423.

31. Cavrois M, Leclercq I, Gout O, Gessain A, Wain-Hobson S, Wattel E: Persistent oligoclonal expansion of human T-cell leukemia virus type 1infected circulating cells in patients with Tropical spastic paraparesis/ HTLV-1 associated myelopathy. Oncogene 1998, 17:77-82.

32. Hanon E, Hall S, Taylor GP, Saito M, Davis R, Tanaka Y, Usuku K, Osame M, Weber JN, Bangham CR: Abundant tax protein expression in $\mathrm{CD}^{+} \mathrm{T}$ cells infected with human T-cell lymphotropic virus type I (HTLV-I) is prevented by cytotoxic T lymphocytes. Blood 2000, 95:1386-1392.

33. Furukawa $Y$, Kubota R, Tara M, Izumo S, Osame M: Existence of escape mutant in HTLV-I tax during the development of adult T-cell leukemia. Blood 2001, 97:987-993.

34. Tamiya S, Matsuoka M, Etoh K, Watanabe T, Kamihira S, Yamaguchi K, Takatsuki K: Two types of defective human T-lymphotropic virus type I provirus in adult T-cell leukemia. Blood 1996, 88:3065-3073.

35. Taniguchi Y, Nosaka K, Yasunaga J, Maeda M, Mueller N, Okayama A, Matsuoka M: Silencing of human T-cell leukemia virus type I gene transcription by epigenetic mechanisms. Retrovirology 2005, 2:64.

36. Doi K, Wu X, Taniguchi Y, Yasunaga J, Satou Y, Okayama A, Nosaka K, Matsuoka M: Preferential selection of human T-cell leukemia virus type provirus integration sites in leukemic versus carrier states. Blood 2005 106:1048-1053

37. Meekings KN, Leipzig J, Bushman FD, Taylor GP, Bangham CR: HTLV-1 integration into transcriptionally active genomic regions is associated with proviral expression and with HAM/TSP. PLoS Pathog 2008, 4: e1000027

doi:10.1186/1742-4690-7-17

Cite this article as: Zane et al:: Tax gene expression and cell cycling but not cell death are selected during HTLV-1 infection in vivo. Retrovirology 2010 7:17.

\section{Submit your next manuscript to BioMed Central and take full advantage of:}

- Convenient online submission

- Thorough peer review

- No space constraints or color figure charges

- Immediate publication on acceptance

- Inclusion in PubMed, CAS, Scopus and Google Scholar

- Research which is freely available for redistribution

Submit your manuscript at www.biomedcentral.com/submit
Biomed Central 